\title{
The Cytokines Responses against Parvovirus B19 in Miscarriage Women and the Susceptibility of their RhD Blood Type to Contract Parvovirus B19 in South of Iraq
}

\author{
Dhurgham Al-Fahad*1, Khalid Majeed ${ }^{2}$, \\ Ahmed Al-Naqshbandi ${ }^{3}$, Ahmed Al-Amery ${ }^{4}$, Bandar Fahad Alharbi ${ }^{5}$
}

\begin{abstract}
Background: Parvovirus B19 (B19) infection is linked with various diseases. Cytokines play critical roles in cellular response to viral infection. It has also been reported that's susceptibility of the ABO blood type people to several viral infection. In this study, we evaluated interleukin 6 (IL-6), interleukin 8(IL-8), and interferon gamma (IFN- $\gamma$ ) levels in aborted women infected with parvovirus B19 (B19+/Abr+) and uninfected with B19(B19-/Abr+) in comparison with healthy women (B12-/Abr-) and susceptibility of their $\mathrm{RhD}$ blood type to contract B19.

Methods: B19+/Abr+ were diagnosed using IgM and IgG antibodies against B19, and the concentrations of IL-6, IL-8, and IFN- $\gamma$ were determined using enzyme-linked immunosorbent assay (ELISA) test in both B19+/Abr+, B19-/Abr+, and B19-/Abr-. Here, we also collected blood groups, number of abortion, and gestational ages from $200 \mathrm{~B} 19+/ \mathrm{Abr}+$ along with the same number ofB19-/Abr+ and B19-/Abr-.

Results: The levels of IFN- $\gamma$ were higher in serum of B19-/Abr+andB19+/Abr+ group in comparison to B19-/Abr-, while the serum levels of IL-6, IL-8were increased in B19+/Abr+ group in comparisontoB19-/Abr+ and B19-/Abr-. Our analyzed data also showed that aborted women with $\mathrm{RhD}+$ are more susceptible to contract s B19 than people with $\mathrm{RhD}$ - blood type.

Conclusions: B19 infection may differently modulate the amount of cytokines in the plasma of aborted women. So, it can be suggested that IL-6, IL-8, and IFN- $\gamma$ potentially useful as markers for inflammation intrauterine. The susceptibility/protection of aborted women against B19 might be determined based on $\mathrm{RhD}$ blood type.
\end{abstract}

Keywords: Aborted women, IL-6, IL-8, IFN- $\gamma$, Parvovirus B19, RhD blood type.

\section{Introduction}

The miscarriage is a common phenomenon that usually occurs in the first trimester of pregnancy between $15 \%-17 \%$ of pregnancies, but the true percentage is likely higher because many miscarriages occur early in the pregnancy without the women even realizing that they are pregnant (1). The miscarriage during pregnancy can be classified into several types. First, incomplete abortion: A condition in which the fetus stops developing, and as a result, part of the contents of the pregnancy is expelled from the uterus, while another part 
remains inside the uterus. This condition is associated with vaginal bleeding of varying degrees of severity. Second, threatened abortion: Vaginal bleeding in the first trimester. In $50 \%$ of these cases, the pregnancy will continue until its normal end. Third, missed abortion: The development of pregnancy and the death of the fetus are halted, as the contents of the pregnancy remain inside the uterus and are not pronounced outside it (2).

Parvovirus B19 (B19) is a common infection that may affect $1-5 \%$ of pregnant women, especially with a normal pregnancy outcome. Infection during pregnancy can cause a variety of other signs of fetal damage. The risk of fetal adverse events increases if the mother's infection occurs during the first trimester of pregnancy but may also occur during the third trimester. It is an important cause of fetal loss throughout pregnancy but has a greater effect in the second half of pregnancy when spontaneous fetal loss for other reasons is relatively rare (3).

There are several immune factors involved in the occurrence of miscarriage, such as alteration in cytokines signaling and viral infection. (4). Thus, cytokines play a crucial role in the regulation and growth of immune cells against viral infections. For example, Tlymphocytes cells (CD4 and CD8) and natural killer cells produce IFN- $\gamma$ naturally which activate at the beginning of an infection by stimulating the dendritic and neutrophilic leukocytes cells (5).

It has also been shown that cytokines play a role in recurrent miscarriage by finding high concentrations of TNF- $\alpha$, IFN- $\gamma$, IL- 2 , IL-4, IL-6, and IL-6 in women who miscarried compared to healthy women $(6,7)$. These concentrations of pro-inflammatory TNF-a and ILs appear to be the major components of pregnancy-associated cytokine networks. Several reports have indicated that the serum levels of TNF-a are elevated in miscarriages and observed that there were high levels of cytokine in supernatants from trophoblastactivated peripheral blood mononuclear cells $(8,9)$.

The defect in immune stimulating cells has been implicated in causing early pregnancy loss. This dysfunction may include defects in cytokines, growth factors, and immunosuppressive agents against viral infection. There are infectious agents that may lead to intrauterine infection in the fetus when the mother is infected during pregnancy, including parvovirus B19. The role of viral infection in spontaneous abortion pathogenesis is controversial (10). The most prevalent pathogen related to fetal loss is the parvovirus-B19 virus (11). It has also been reported that $\mathrm{ABO}$ blood types might have a potential importance in relevance to contracting a viral infection. While some studies examined no significant correlation between $\mathrm{ABO}$ blood types and the effect of viral infection (12). Therefore, we aimed to measure the level of cytokines in aborted women infected and uninfected by parvovirus B19 and their RhD blood type to contract parvovirus B19 to fill in the knowledge gap in this field. IFN- $\gamma$ is produced predominantly by natural killer cells and CD4 Th1 and CD8 cytotoxic $\mathrm{T}$ lymphocyte effector $\mathrm{T}$ cells once antigen-specific immunity develops as part of the immune response $(13,14)$.

\section{Materials and Methods Study population}

This study was carried out in Maternity Hospital (Bunt al Huda) in Nassiriyah city/ Iraq from January 2019 and February 2020. The hospital's ethics committee has approved the study and informed consent was obtained from patients before blood sampling. From a total population of $200 \mathrm{~B} 12+/ \mathrm{Abr}+, 200 \mathrm{~B} 12-$ /Abr+ and 200 B12-/Abr- have been taken. Then, their gestational age, number of abortions, and blood groups were collected along with the same number of healthy samples in a study local population. 


\section{Determination of the cytokine concentration in the plasma}

The plasma levels of IL-6), IL-6, and IFN- $\gamma$ were detected using ELISA Test Kits provided by (EUROIMMUN AG, Luebeck Germany). According to manufacturer's instructions, briefly, assessment of IL-6, IL-8, and IFN level in serum by ELISA method. There are two immunological steps in this method. First, the cytokine is captured by a monoclonal antibody attached to the wells. Second, a monoclonal antibody interacted with a biotinylated monoclonal antibody is added together with Streptavidin-peroxidase conjugate. The antibody-antigen interaction binds the conjugate. After incubation, the wells were washed, and the antigen complex interacted with the well detected by the addition of a chromogenic substrate.

Blood samples and blood groups were collected from 200 B12+/Abr+, 200 B12-
/Abr+, and 200 B12-/Abr-, this was considered as the key criteria for eligibility to be included in this study. Blood type data were collected from the same number of B12+/Abr+, 200 B12-/Abr+, and 200 B12/Abr- individuals from the same hospitals.

\section{Statistical analysis}

Statistical analysis was performed by SPSS version 15-, and one-way ANOVA test was performed, $\mathrm{p}$ value of $>0.05$ was considered to indicate statistical significance.

\section{Results}

Determination of the IL-6, IL-8 and IFN- $\gamma$ concentration in the plasma

The amount of IL-6, IL-8, and IFN- $\gamma$ in the plasma of patients (B12+/Abr+ and B12/Abr+) and healthy control individuals (B12(Abr-) were measured in plasma as mentioned in Table.1.

Table 1. Cytokines level among B12+/Abr+, B12-/Abr+andB12-/Abr-.

\begin{tabular}{llllll}
\hline & $\begin{array}{l}\text { Healthy control } \\
\text { N: 200 } \\
\text { Mean } \pm \text { SD }\end{array}$ & $\begin{array}{l}\text { Aborted women have not } \\
\text { infected with B19 virus } \\
\mathbf{N}: \mathbf{7 3} \\
\text { Mean } \pm \text { SD }\end{array}$ & $\begin{array}{l}\text { Aborted women have } \\
\text { infected with B19 virus } \\
\text { N: 127 } \\
\text { Mean } \pm \text { SD }\end{array}$ & p. value & Significance \\
\hline IL-6 & $350.78 \pm 232.69^{\text {ab }}$ & $398.14 \pm 287.94^{\mathrm{b}}$ & $689.44 \pm 536.03^{\mathrm{c}}$ & 34.98 & 0.005 \\
\hline IL-8 & $17.19 \pm 11.49^{\mathrm{a}}$ & $51.47 \pm 44.77^{\mathrm{b}}$ & $84.1 \pm 52.23^{\mathrm{c}}$ & 135.82 & 0.005 \\
\hline IFN- $\boldsymbol{\gamma}$ & $91.86 \pm 6.52^{\mathrm{a}}$ & $116.36 \pm 27.08^{\mathrm{bc}}$ & $116.51 \pm 31.11$ & $65.58^{\mathrm{c}}$ & 0.005 \\
\hline
\end{tabular}

*Combined letters mean no significant difference between groups.

The plasma levels of IL- 6 are significantly $(\mathrm{p}<0.005)$ increased in B12+/Abr+ in comparison with B12-/Abr- and B12-/Abr+, while IL-6 levels in both B12-/Abr- and B12/Abr+ groups were not significant (Fig. 1A). Plasma IL-8 concentrations of B12-/Abr+ and $\mathrm{B} 12+/ \mathrm{Abr}+$ were significantly higher than B12-/Abr-. The amount of IL-8 in plasma of B12-/Abr+ was significantly $(\mathrm{p}<0.05)$ lower than in plasma of B12+/Abr+ (Fig. 1B). The averages of IFN- $\gamma$ concentrations in the plasma ofB12+/Abr+, B12-/Abr+ did not differ significantly (Fig. 1A). Nevertheless, IFN- $\gamma$ levels B12+/Abr+, B12-/Abr+ group were significantly $(\mathrm{p}<0.05)$ compared with B12-/Abr- (Fig. 1B).

\section{The susceptibility of RhD blood type to contract B19}

To study the association between blood groups and parvovirus B12 among B12+/Abr+, 200 B12-/Abr+, gestational ages and number of abortion, $200 \mathrm{~B} 12+/ \mathrm{Abr}+, 200 \mathrm{~B} 12-/ \mathrm{Abr}+$, and 200 B12-/Abr- were taken in this local population study. Our data analysis demonstrated that the proportion of $\mathrm{B} 12$ patients with $\mathrm{RhD}$ - is significantly lower than the $\mathrm{RhD}+$ patients in each of the (B12+/Abr+, 
B12-/Abr+, and B12-/Abr-) (Fig. 2), gestational ages (Figs. 3 and 4), and the number of abortion (Figs. 5 and 6) suggesting that the risk of contracting B12 was higher among $\mathrm{RhD}+$ patients compared to the RhD- patients. Our results also showed that women with a first miscarriage and gestational ages $1^{\text {st }}$ with $\mathrm{RhD}+$ exposed to infection with the parvovirus $\mathrm{B} 12$ are more susceptible to infection than the negative RhD-.
A

\section{IL-6}

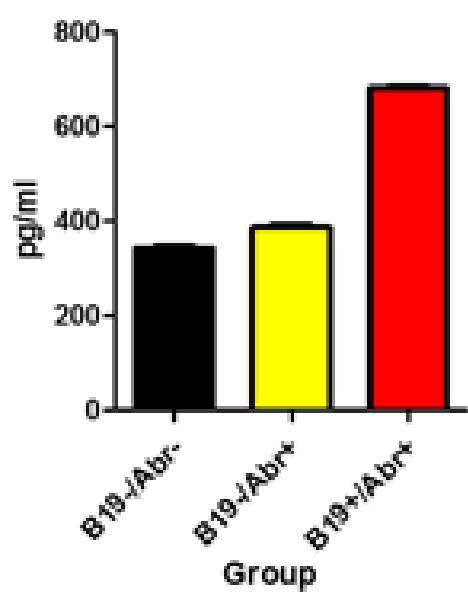

B

IL-8

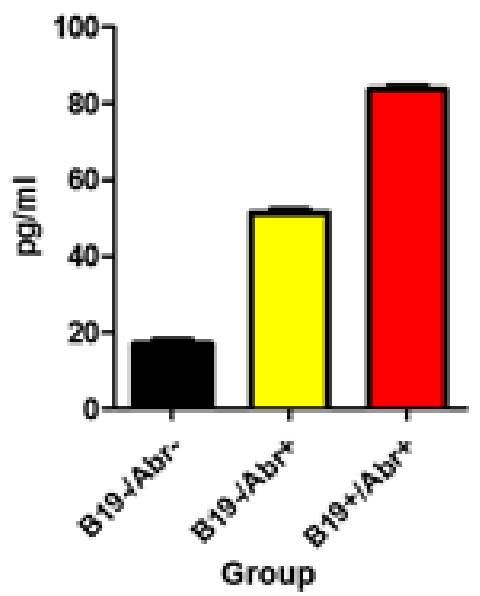

C

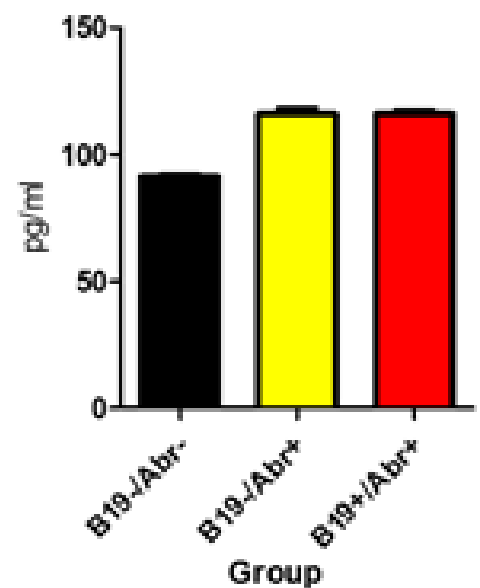

Fig. 1. The amount of IL-6 and IL-8 and IFN- $\gamma$ in plasma of patients (B12+/Abr+ and B12-/Abr+) and healthy control individuals (B12-/Abr-). (A) The levels of IL-6, (B) the levels of IL-8. and (C) the levels of IFN- $\gamma$. The results significant $\mathrm{p}<$ $0.05, \mathrm{p}<0.005$.

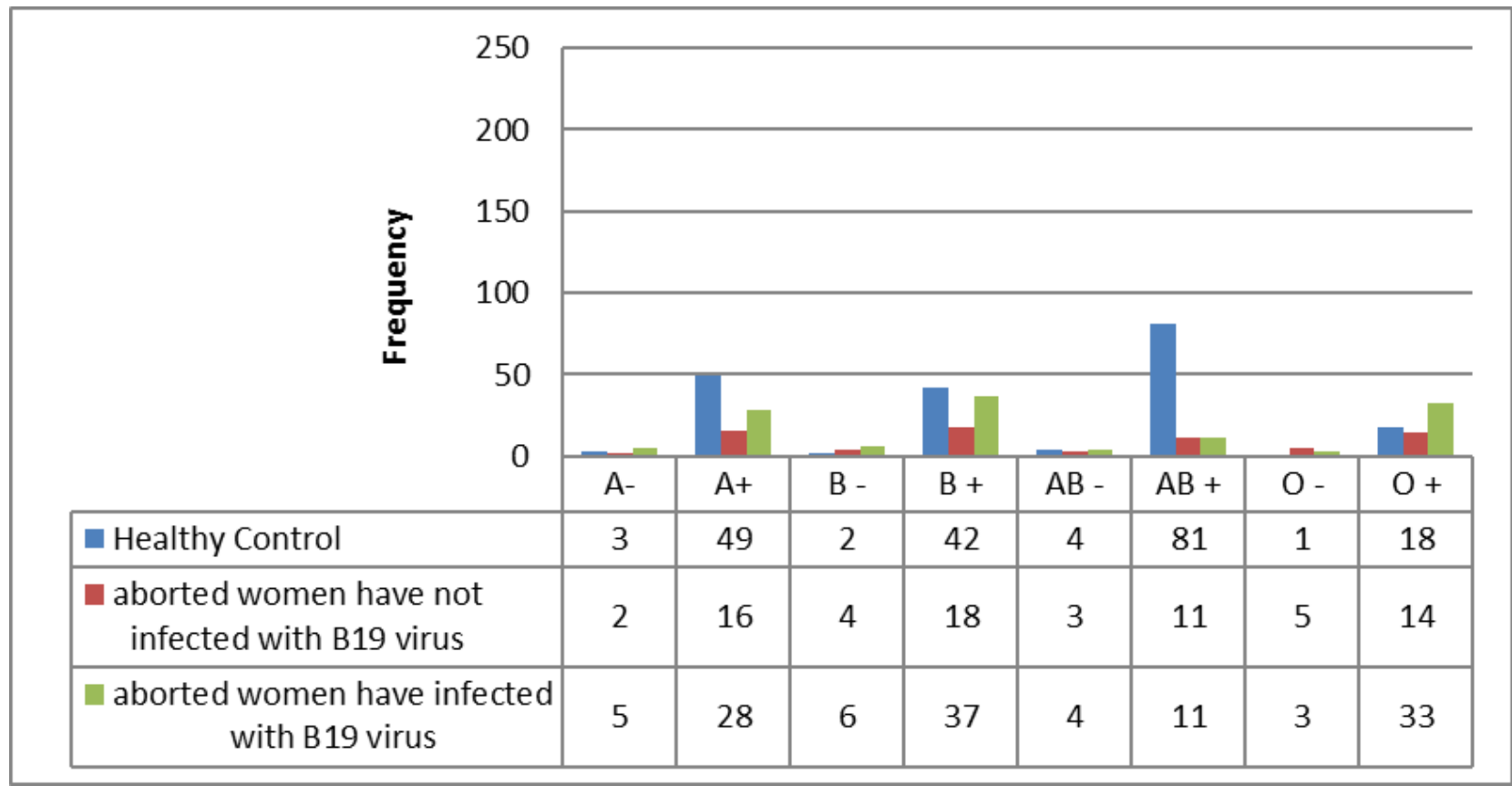

Fig. 2. Frequency various blood types in relation to B12+/Abr+, B12-/Abr+andB12-/Abr-. 


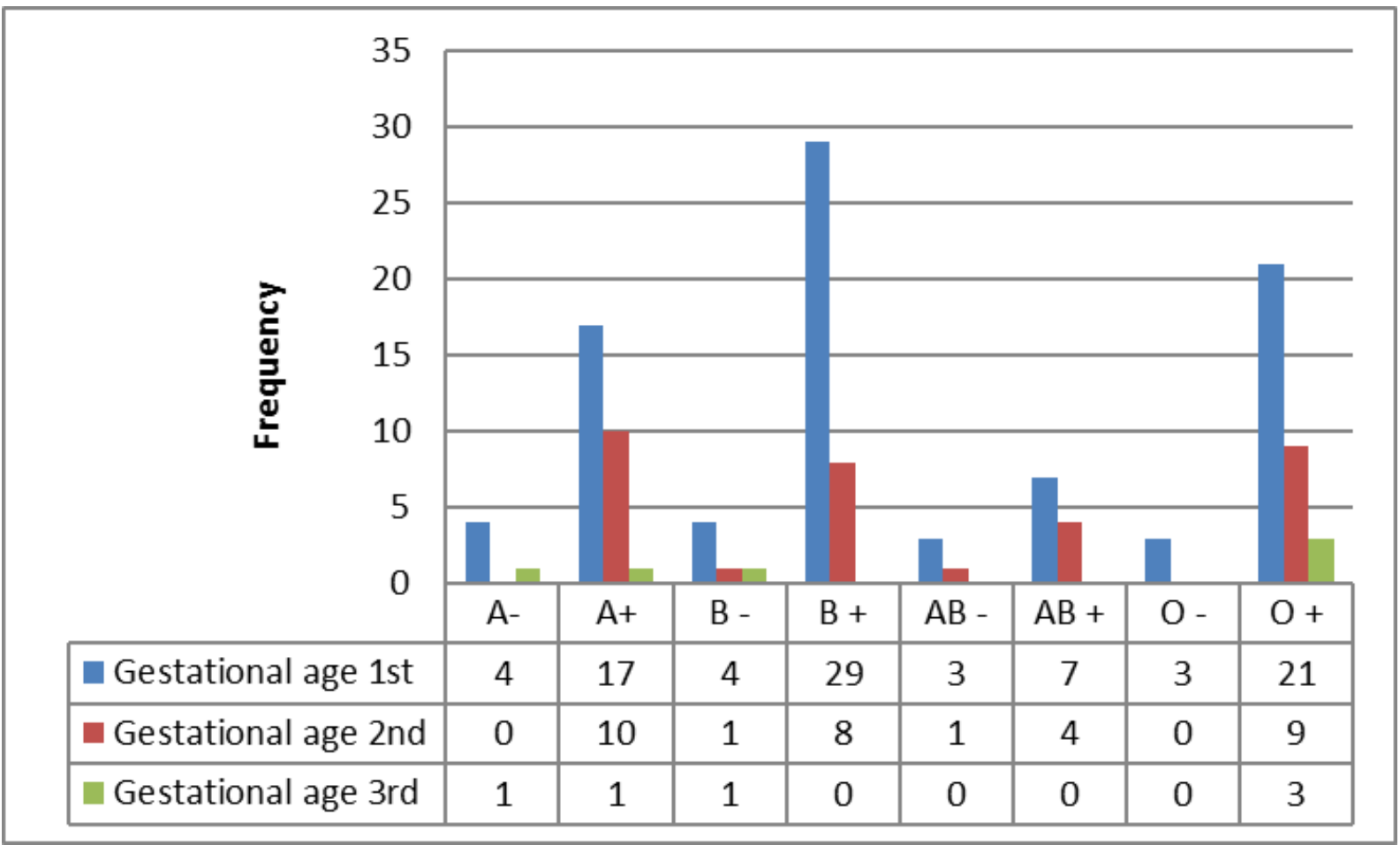

Fig. 3. Frequency various blood types in relation to gestational ages.

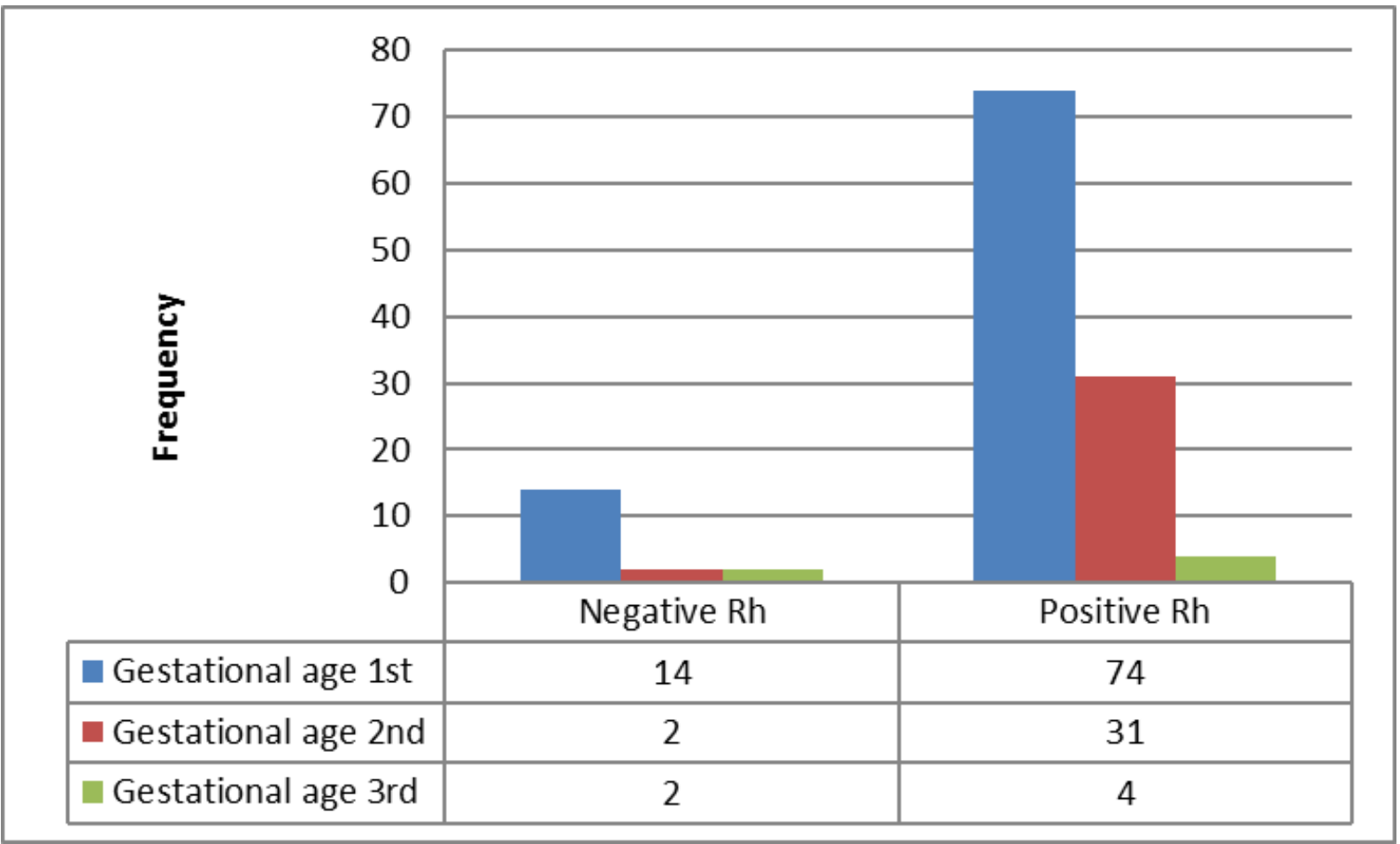

Fig. 4. Frequency Rh blood types in relation to gestational ages. 


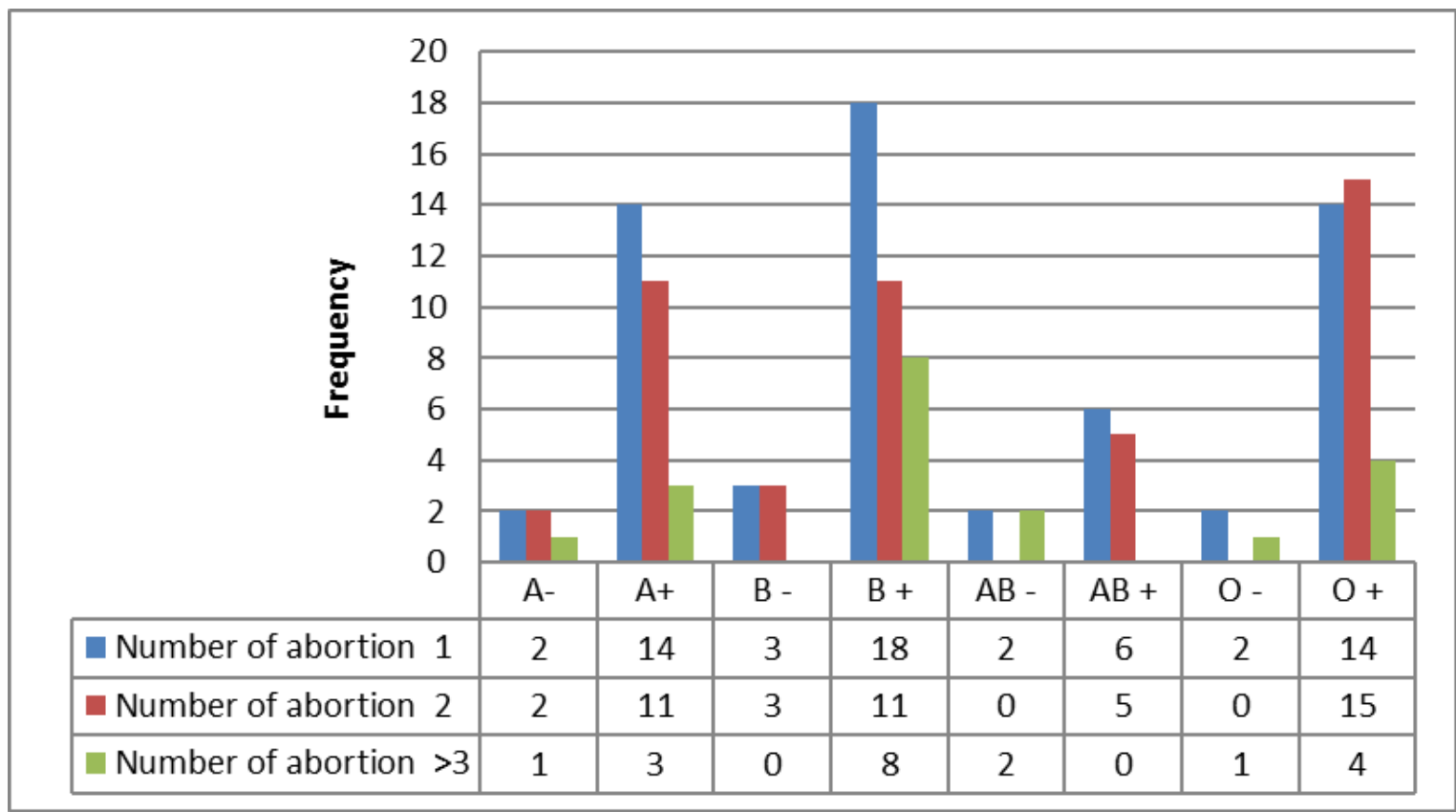

Fig. 5. Frequency various blood types in relation to number of abortions.

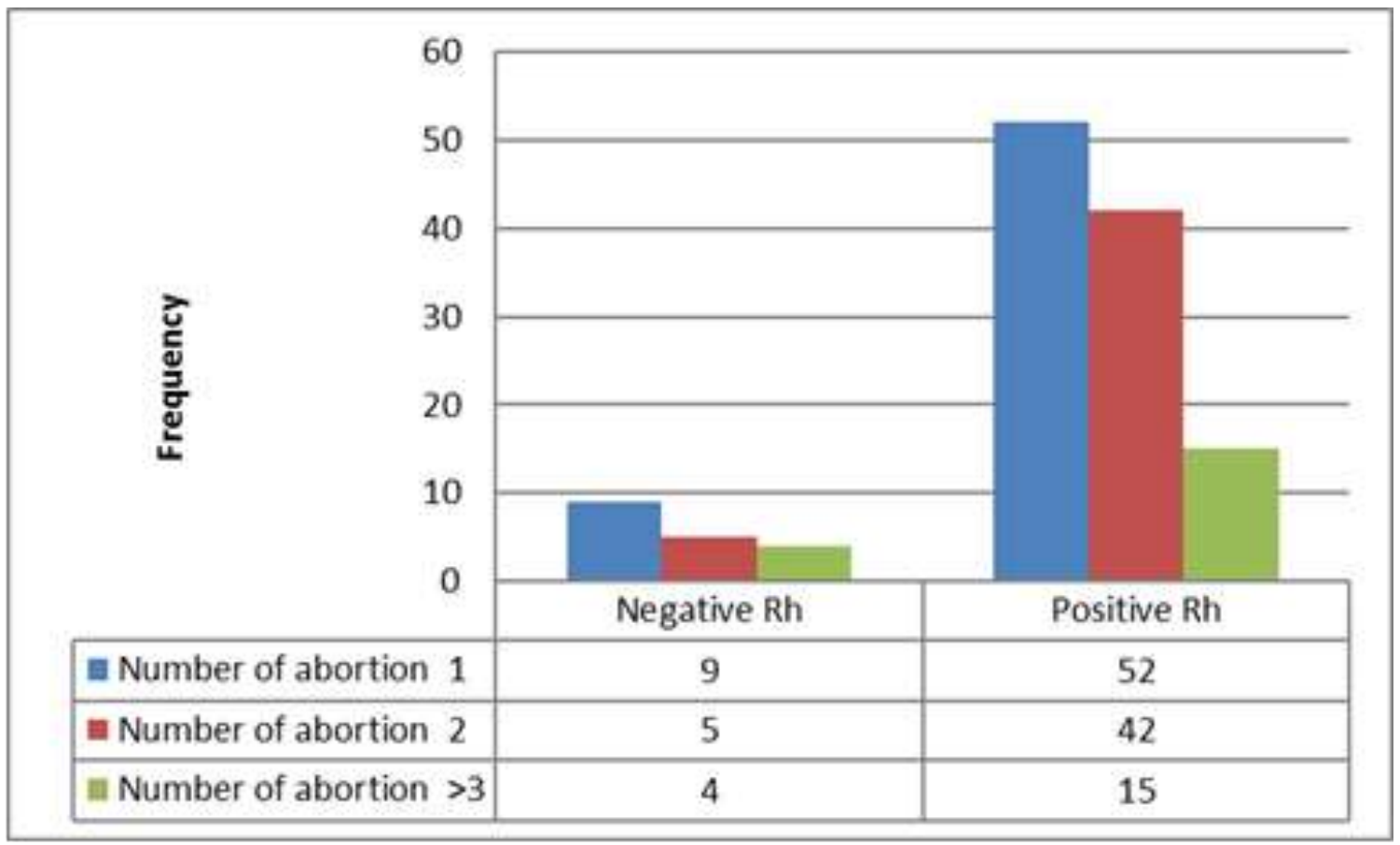

Fig. 6. Frequency Rh blood types in relation to number of abortions.

\section{Discussion}

It has been demonstrated that B19 infection is associated with elevated circulating levels of interferon and interleukins that are linked with several diseases (15). However, little attention has been given to evaluate the levels of IL-6, IL-8 and IFN- $\gamma$ in aborted women infected
(B19+/Abr+) and uninfected (B19-/Abr+) with B12. Our results reported that levels of IL-6, and IL-8 significantly increase in B19+/Abr+ and B19-/Abr+ in comparison with B12-/Abr(Figs. 1A and B), while and IFN- $\gamma$ significantly increase in both B19+/Abr+ and 
B19-/Abr+ in comparison with B12-/Abr(Fig. 1C).

It has been reported that cytokines involved in inflammatory and infection responses, such as IL-6 and IL- 8 have been shown to be a multifunctional cytokine including an inflammatory marker for various viral infections such as COVID-19 (16), and regulatory functions in embryo implantation (17). They are widely expressed in the female reproductive system and transfer the signaling in women prone to recurrent miscarriage and thus insufficient local of IL-6 and IL-8 may also contribute to fetal loss. IL-6 expression decreases in the endometrium in women with recurrent miscarriage $(18,19)$.

IFN- $\gamma$ is critical for the immune response against viral and bacterial infections, and a vital activator of macrophages and enhancer of major histocompatibility complex class 11 . It also plays an important role in the immune system via inhibiting viral replication directly. It has also been reported that uterine natural killer cells produce high levels of IFN- $\gamma$ during pregnancy which in turn dilates and thins the walls of maternal spiral arteries to promote the flow of blood to the implantation locate. This leads to the maturity of the placenta (20). IFN- $\gamma$ was identified to be produced during the early stages of pregnancy. It is richly generated by uterine natural killer cells in the maternal endometrium (21).

The ABO blood types are identified to be coupled with several human diseases (22-25). While the connection between the RhD blood type and different diseases has not been fully established yet. Here, we reported that RhDblood type provides protection of aborted women against B19.RhD+has been demonstrated to be linked with high infection among B19 patients in a population in the south of Iraq. As previous studies have shown that people with RhD- blood were more susceptible to contract viral infection than people with $\mathrm{RhD}+$ blood type. The mechanisms behind this susceptibility are ambiguous. Moreover, we could say that the association between blood types (ABO and $\mathrm{RhD}$ ) and B19 is possible to be based on several factors including ethnicity, environmental location, and contact with infected patients.

This could be due to the presence of antiA17 and/or anti-B antibodies in the circulation and their ability to bind to the proteins of the virus, thereby preventing them from entering cells. markedly, a genome-wide connection study has confirmed the potential involvement of the $\mathrm{ABO}$ blood group system in contracting COVID-19 (26). Although few studies have specifically established a linkage between $\mathrm{RhD}$ blood type and susceptibility to viral infection, a recent study reported a high-risk association between RhD+, COVID-19 infection, and resulting deaths (27-28). However, the correlation between the blood types and B19 infection has not yet been fully established. Hence, we explained the potential connection between, RhD and B19.

Most women with B19 infection during pregnancy face a high risk of fetal loss. Early diagnosis can be made by measuring cytokine levels, which can be considered as an indicator of viral infection in pregnant women. In this study significant change in levels of serum IFN- $\alpha$, IL-6, and IL-8 in miscarriage infected with B19 and miscarriage uninfected with B19 compared to normal pregnant women this indicates that increased levels of IFN- $\alpha$, IL-1 $\beta$, and IL- 6 are responsible for response against B12 infection in miscarriage.

\section{Acknowledgements}

We thank the Maternity Hospital (Bunt al Huda) in Nassiriyah city/ Iraq providing the samples and data to carry out this study. The authors declare they have no conflict of interest. 


\section{References}

1. Cohain JS, Buxbaum RE, Mankuta D. Spontaneous first trimester miscarriage rates per woman among parous women with 1 or more pregnancies of 24 weeks or more. BMC Pregnancy and Childbirth. 2017;17(1):437.

2. Bricker L, Farquharson RG. Types of pregnancyloss in recurrent miscarriage: implications for research and clinical practice. Hum Reprod. 2002;17(5):1345-50.

3. Giorgio E, De Oronzo MA, Iozza I, Di Natale A, Cianci S, Garofalo G, et al. Parvovirus B19 during pregnancy: a review. J Prenat Med. 2010;4(4):63-6

4. Zhang J-M, An J. Cytokines, inflammation, and pain. Int Anesthesiol Clin. 2007;45(2):27-37. 5. Ali S, Mann-Nüttel R, Schulze A, Richter L, Alferink J, Scheu S. Sources of Type I Interferons in Infectious Immunity: Plasmacytoid Dendritic Cells Not Always in the Driver's Seat. Front Immunol. 2019;10:778.

6. Ma J, Zhang X, He G, Yang C. Association between TNF, ILIB, IL6, ILIO and IFNG polymorphisms and recurrent miscarriage: a case control study. Reprod Biol Endocrinol. 2017; $15: 83$.

7. Camil L, Viorica E. Interleukin-6 and interleukin-10 gene polymorphisms and recurrent pregnancy loss in Romanian population. Iran $\mathbf{J}$ Reprod Med. 2014;12(9):617-622.

8. Yockey LJ, Iwasaki A. Interferons and Proinflammatory Cytokines in Pregnancy and Fetal Development. Immunity. 2018;49(3):397412.

9. Austgulen R, Lien E, Liabakk N-B, Jacobsen G, Arntzen KJ. Increased levels of cytokines and cytokine activity modifiers in normal pregnancy. Eur J Obstet Gynecol Reprod Biol. 1994;57(3):149-55.

10. Giakoumelou S, Wheelhouse N, Cuschieri K, Entrican G, Howie SEM, Horne AW. The role of infection in miscarriage. Hum Reprod Update. 2016;22(1):116-33.

11. Shabani Z, Esghaei M, Keyvani H, Shabani F, Sarmadi F, Mollaie H, et al. Relation between parvovirus B19 infection and fetal mortality and spontaneous abortion. Med J Islam Repub Iran. 2015;29:197.

12. Göker H, Aladağ Karakulak E, Demiroğlu H, Ayaz Ceylan Ç M, Büyükaşik Y, Inkaya A, et al. The effects of blood group types on the risk of COVID-19 infection and its clinical outcome. Turk J Med Sci. 2020;50(4):679-683.

13. Schoenborn JR, Wilson CB. Regulation of Interferon- $\gamma$ During Innate and Adaptive Immune Responses. Adv Immunol. 2007;96:41-101.

14. Artis D, Spits H. The biology of innate lymphoid cells. Nature. 2015;517:293-301.

15. Isa A, Lundqvist A, Lindblom A, Tolfvenstam $\mathrm{T}$, Broliden $\mathrm{K}$. Cytokine responses in acute and persistent human parvovirus B19 infection. Clin Exp Immunol. 2007;147(3):419-425.

16. Tang Y, Liu J, Zhang D, Xu Z, Ji J, Wen C. Cytokine Storm in COVID-19: The Current Evidence and Treatment Strategies. Front Immunol. 2020;11:1708.

17. Guzeloglu-Kayisli O, Kayisli UA, Taylor HS. The role of growth factors and cytokines during implantation: endocrine and paracrine interactions. Semin Reprod Med. 2009;27(1):62-79.

18. Ticconi C, Pietropolli A, Di Simone N, Piccione E, Fazleabas A. Endometrial Immune Dysfunction in Recurrent Pregnancy Loss. Int J Mol Sci. 2019;20(21):5332.

19. Jasper MJ, Tremellen KP, Robertson SA. Reduced expression of IL-6 and IL-1alpha mRNAs in secretory phase endometrium of women with recurrent miscarriage. J Reprod Immunol. 2007;73(1):74-84.

20. Ashkar AA, Di Santo JP, Croy BA. Interferon gamma contributes to initiation of uterine vascular modification, decidual integrity, and uterine natural killer cell maturation during normal murine pregnancy. J Exp Med. 2000;192(2):259-270.

21. Murphy SP, Tayade C, Ashkar AA, Hatta K, Zhang J, Croy BA. Interferon gamma in successful pregnancies. Biol Reprod. 2009;80(5):848-59. 
22. Cheng Y, Cheng G, Chui CH, Lau FY, Chan $\mathrm{PK}, \mathrm{Ng} \mathrm{MH}$, et al. ABO blood group and susceptibility to severe acute respiratory syndrome. JAMA. 2005;293(12):1450-1.

23. Borén T, Falk P, Roth KA, Larson G, Normark S. Attachment of Helicobacter pylori to human gastric epithelium mediated by blood group antigens. Science. 1993;262(5141):1892-5. 24. Wang DS, Chen DL, Ren C, Wang ZQ, Qiu $\mathrm{MZ}$, Luo HY, et al. ABO blood group, hepatitis $B$ viral infection and risk of pancreatic cancer. Int J Cancer. 2012;131(2):461-8.

25. Loscertales MP, Owens S, O'Donnell J, Bunn J, Bosch-Capblanch X, Brabin BJ. ABO blood group phenotypes and Plasmodium falciparum malaria: unlocking a pivotal mechanism. Adv Parasitol. 2007;65:1-50.
26. Ellinghaus D, Degenhardt F, Bujanda L, Buti $\mathrm{M}$, Albillos A, Invernizzi $\mathrm{P}$, et al. Genomewide Association Study of Severe Covid-19 with Respiratory Failure. N Engl J Med. 2020;383(16):1522-34.

27. Al-Fahad D, Vaiyapuri S. Blood types and their relationship with COVID-19 among a study population in Iraq. University of Reading. 2020. 28. Majeed KR, Al-Fahad D, Jalood HH, Mrtatha K A. Sumiktsal S, Harry F W, et al. $\mathrm{RhD}$ blood type significantly influences susceptibility to contract COVID-19 among a study population in Iraq. F1000Research. 2021;10:38. 